\title{
Entrevista com Erika Fischer Lichte
}

Por Matteo Bonfito

Transcrição: Andrea Paula Justino dos Santos

O Professor (Marvin) Carlson me disse, além de estar escrito no prefácio de seu livro ${ }^{1}$, que em alemão, diferente da abordagem feita por (Richard) Schechner, não há diferença entre teatro e performance. Você poderia falar um pouco sobre isso?

Nosso conceito de performance é mais amplo, enquanto que, para Schechner e os falantes da língua inglesa, esse conceito é mais restrito. Em inglês, quando se fala em teatro, pensa-se em dramaturgia; enquanto na Alemanha, falamos em teatro quando há performances, sejam elas provindas da dramaturgia, do teatro não dramático, da dança ou ópera etc. $E$, além disso, também falamos em teatro quando alguém faz uma cena na rua, mesmo que não seja algo muito elaborado, mas com pessoas assistindo. Quando os estudos teatrais surgiram na Alemanha dentro da academia, começaram como uma disciplina sobre performances. Isso foi muito bem colocado por Max Herrmann, o fundador dos estudos teatrais aqui em Berlim. Tínhamos disciplinas de literatura, mas o foco estava no texto; não tínhamos algo sobre performances. E uma vez que precisávamos de uma, a disciplina acadêmica Estudos Teatrais foi criada, com o objetivo de lidar com as performances. Por que é assim, é difícil dizer, pois a discussão em inglês envolve a diferença entre teatro e performance. Para nós, tudo é teatro.

Então, não há dicotomia.

Não.

Sobre o conceito de performativo: de acordo com o que está em seu livro, umas das caracteristicas do performativo é exatamente a dissolução de dicotomias, uma vez que você afirma que performativo é algo autorreferencial e constitutivo de realidade, considerando também a abordagem de (J.L.) Austin².

Essa é a abordagem de Austin, que você não pode utilizar para outros, porque se você considera o ato da fala, por exemplo, "Eu vos declaro marido e mulher", essas são palavras executando o que é dito, isso é autorreferencialidade; elas

1.

The Transformative Power of Performance, a new aesthetics. (2008)
2. How to Do Things with Words. 
não se referem a algo fora, elas estão executando exatamente aquilo que elas dizem. Está implícito que o padre tem o poder de fazer isso, "Eu vos declaro marido e mulher", então está feito. E, portanto, é constitutivo de uma nova realidade social; eles agora estão casados, têm certos direitos e deveres. Isso é muito importante sobre o conceito desenvolvido por Austin a língua não é algo que descreve certos estados e processos que possam acontecer, mas a língua, por si mesma, tem o poder de agir. E quando ela age, uma nova realidade social surge.

Você também se refere às contribuições de Judith Butler.

Sim, ela leva isso a outro nível, pois ela fala de identidade. As ideias antigas referiam-se à identidade como algo inato, por exemplo, uma semente em uma árvore; a árvore desabrocha - desde o século XVIII, essa é a noção ocidental de identidade. Na verdade, o modelo dominante era: há uma essência que é revelada. Já Butler reverte esse pensamento: ela diz, não, nós produzimos nossa identidade através de certos atos. A partir daí, produzimos identidade e podemos mudar isso o tempo todo, se produzirmos outros atos corporais. E isso é importante, identidade não é algo que eu expresso através de meus atos performativos, mas algo que é produzido através de meus atos performativos. Eles significam o que exatamente o que fazem, e constituem novas realidades, que pode ser minha identidade.

Uma das dúvidas que surgiram quando eu li seu livro foi sobre a relação entre o teatral e o performativo. Esses conceitos estão inter-relacionados?

Sim, com certeza. Quer dizer, o teatral é sempre performativo. Não consigo pensar em nada que seja teatral e não seja performativo, porque o teatral sempre executa aquilo que indica, e produz essa realidade de teatro que significa o que realiza. Mas a diferença é quando alguém diz que algo é teatral, então isso é executado com o intuito de ser percebido pelos outros; encontra-se nessa consciência, quando eu realizo, esse ato é ou será percebido pelos outros - isso é teatral, executar para ser percebido. Quanto ao performativo, quando eu produzo minha identidade a partir desses atos, pode-se dizer que para a identidade ser reconhecida pelos outros, os outros têm que reconhecer essa identidade. Assim será. Mas, pode ser também, por exemplo, quando estou lendo um livro e certas emoções surgem, há um impacto em mim e ninguém percebe - isso é performativo, mas não é teatral. Assim sendo, eles se entrelaçam frequentemente, mas têm significados diferentes. Mas teatral é sempre performativo, mas não todo performativo é teatral. 
Então, o relacionamento entre o performativo e o teatral é que, com o intuito de fazer algo acontecer, o performativo se torna necessário, certo?

Sim, e isso é o performativo, mas se você fizer algo acontecer, apenas deixe acontecer, isso é o performativo. Mas quando você executa algo, você deixa acontecer, mas tem alguém que vê ou que percebe o que está acontecendo, então, isso é teatral.

\section{A intencionalidade tem um papel importante então?}

Não tanto, porque a intencionalidade normalmente significa que você quer transmitir algo em particular. Quer dizer, se nós estivéssemos sentados em um café conversando e percebêssemos alguém nos observando, de repente começaríamos a nos comportar de maneira diferente - isso é teatral, saber que você é percebido. Isso é que é importante. Não tanto as intenções, mas a consciência de ser percebido.

Entendo, mas a intencionalidade não está envolvida na representação? Por exemplo, se faço uma montagem de Hamlet, tenho uma visão particular sobre isso e quero compartilhar com o público. O que você pensa disso?

Se fizermos algo, há intencionalidade, caso o contrário não faríamos. Mas o que acontece com aquilo que realizamos, isso nós não podemos decidir; podemos pensar de uma forma e o resultado ser o contrário. Se você tem uma visão a ser compartilhada sobre Hamlet, executa certas coisas no palco, e eu recebo tudo isso de maneira muito diferente da sua intenção, então talvez sua visão não me interesse; mas o que me interessa é o que percebo, e o que faço com isso. E isso, penso, é muito importante sobre a performance. E não podemos utilizar esse modelo do transmissor/receptor; isso não funciona, porque o processo de onde todas as coisas emergem, ninguém, nem mesmo o espectador que passa pela experiência, nem os que a executaram, jamais poderão imaginar que será daquela determinada maneira. Vem do nada, e isso é importante. No Ocidente, damos um foco muito grande para a intencionalidade. Certo, isso acontece, pois pretendemos algo, mas temos que entender que os outros vão receber isso que realizamos com a melhor das intenções de maneira diferente. Posso transmitir, mas o resto não é possível. E temos que entender isso.

Quando você fala em materialidade em seu livro, refere-se ao processo no qual os atores ou performers não pretendem representar algo, mas criar um espaço para os espectadores lerem ou receberem isso. 
Receber; eu não diria ler, porque ler é apenas intelectual, e o interessante sobre as performances é que envolve tudo: intuições, emoções, respostas, energia; envolve tudo isso mais a cognição. Eu não separaria uma coisa da outra. Tudo está envolvido e já que cada um de nós traz consigo alguma coisa para dentro da performance, as respostas serão diferentes. Mas existem momentos no teatro - e isso é especial - quando as pessoas parecem responder de maneira parecida, por exemplo, quando todo mundo ri ou quando - isso não é tão comum hoje em dia, mas costumava ser - as pessoas começam a chorar, ou de repente elas ficam quietas; havia barulho, pessoas movendo objetos, mas há um determinado momento em que há um absoluto silêncio, nada acontece. É estranho, estão respondendo da mesma maneira; são grandes momentos quando isso acontece.

Em relação a serem produtores de eventos corporificados, você reconhece especificidades relacionadas ao trabalho do ator e do performer? Quando falo em performer, quero dizer aquele que produz performance art.

Para mim, todo mundo é performer; o ator é sempre um performer, mas não todo performer é um ator. No final, eu não vejo muita diferença, porque se você realiza certo evento, isso é importante para você; tem a ver com sua autobiografia, ou como Marina Abramovic fez algumas vezes com seu corpo, ou se você começa a representar um papel, será sempre para uma plateia que você executará coisas que terão um impacto emocional. Em alguns casos, o aspecto emocional domina, quer dizer, é difícil olhar para uma pessoa quando ela está machucando a si mesma sem sentir fortes emoções. Mas, quando um ator finge estar atacando alguém, vai depender da sua capacidade de imaginação; aqueles que têm grande imaginação responderão quase que da mesma maneira, sabendo muito bem que a pessoa não está realmente machucada, mas que se trata de um personagem trágico. Mas, pode haver identificação, a ponto de sentirem a mesma coisa que o personagem. Então, penso que depende do tipo de espectador que você tem, do tipo de receptor. Conheço muita gente - por exemplo, Schechner fez isso por muito tempo, agora está de volta ao teatro - que diz que isso é horrível, que aquilo é legal, representação é ruim não vejo porque representação seria algo tão ruim. É possível viver em um mundo sem representação? Não podemos, e não acho que deveríamos. Acredito que essa atitude é olhar só um lado das coisas, se você encontra algo novo, então o que existia antes não serve mais. Foi o que Schechner fez em Dyonisius'69: ele colocou em primeiro plano a participação do público, nem que fosse só para dançar, e parece que tudo começou ali, mas sempre existiu. Portanto, essa dicotomia com o ator fazendo 
um papel, e o performer fazendo outra coisa, não faz sentido, pois uma vez que há um público, sempre haverá um papel. Eles podem machucar seus corpos, mas estão fazendo o papel de quem machuca. Caso contrário, há a questão, vejo ou não estou vendo? É maravilhoso em Beckett, quando a pessoa diz, sou tanto quanto sou visto? Essa é a questão. Quando sou visto? Então, o comportamento é o mesmo para um ator, um performer ou uma pessoa na rua.

Isso é interessante, então você acha que não há diferença no fato do performer não trabalhar com personagens e estórias.

Não. Aliás, hoje eles trabalham com estórias e personagens, e o teatro trabalha com coisas que a performance art fazia antes, tudo está misturado. Penso que os espetáculos atendem a certas necessidades de um determinado tempo. No século XVII, os atores atendiam ao propósito de serem uma representação do príncipe e da religião, e eles executavam essa função. Hoje, não temos isso, os atores ou entretêm ou ajudam pessoas a refletir sobre isso ou naquilo; ou pretendem conscientizar as pessoas de coisas que acontecem no momento. Seja lá o que for, tem que a ver com o tempo; portanto, penso que não deveríamos dar tanta ênfase a isso.

São processos históricos.

Sim, não tem tanta importância.

Gostaria de perguntar sobre ficcionalização; você escreveu um artigo, que na verdade eu não li, sobre esse assunto, certo?

Acho que sim, há um tempo, lembro vagamente que fiz algo assim.

Baseado no que acabou de dizer, você acha que há graus de ficcionalização? Ou ficção é produzida pelo espectador?

Sim, quer dizer, essa é minha perspectiva. Quando olho para o palco e vejo Ulrich Matthes, ele faz isso e aquilo; (...), ela faz isso e aquilo. Certo, mas quando eu mudo a perspectiva, por exemplo, o que Tio Vanya está fazendo? Como Elena responde? Então, é outra perspectiva. A ficção surge porque eu estou pronto e aberto a aceitar que estão mostrando algo que algumas pessoas em um mundo ficcional fizeram. Mas isso depende se vou aceitar ou não. Senão, só me questiono sobre o que estão fazendo lá e não ligo se faz sentido ou não.

Então, ficção não depende da intenção do artista, mas da atitude do espectador? 
Ambos, o artista tem suas intenções e há também as instituições - por exemplo, quando ele trabalha para o Deutsches Theater. Dimiter Gotscheff, ou quem mais trabalhar por lá, sabe que as pessoas estão abertas a aceitar um tipo de ficção, e então é isso o que fazem, mas o que eu faço a partir dessa ficção, isso é pessoal. Claro, isso tem a ver com toda a base cultural; vejo isso acontecer com os colegas ${ }^{3}$ aqui quando vamos juntos ao teatro, há diferentes respostas, que às vezes são pessoais e outras culturais. Tudo bem. Por outro lado, quando você vê a última produção de (...) que viajou pelo mundo todo, mais de 300 apresentações.

\section{Eu assisti.}

Foi um grande sucesso por onde passou. E isso é extraordinário, havia algo na qualidade da atuação, na presença extraordinária de (...), a energia, algo quase algo animal, essa energia que ele transferia e qualquer ser humano podia se sentir sintonizado. E não foi preciso haver uma base cultural em comum, mas você reagia ao que estava lá, e isso é algo interessante. Isso só se aplica ao teatro, onde há um ser humano na sua frente, não uma imagem; você está lá e pode sentir essa energia, e invoca essa energia em você.

Quando fala em presença, você diferencia uma noção fraca, forte e radical de presença. Você considera a ausência como produtora de presença?

Depende, se alguém estava lá e sai, sua presença pode ainda ser sentida. Ou quando você espera por algo que deveria estar lá, a ausência se mantém; então, essa ausência pode ser um tipo de presença. Mas, não é uma energia que se emana. É apenas para você, um sentimento de que algo está faltando, uma perda ou algo assim.

Você menciona em seu livro que a questão da presença não está resolvida, é algo em aberto. Desde a publicação do livro, você encontrou outros aspectos dessa questão?

$\mathrm{Eu}$ não lido com isso mais. Eu normalmente espero o assunto voltar. Quer dizer, quanto a isso, eu trabalho de um jeito arcaico, porque se quando sento para escrever, sinto que há um bloqueio, sinto no meu estômago, então eu não escrevo. Quando sento e começa a fluir, eu escrevo à mão. E flui. Quando estou trabalhando em algo que produzi no passado, dois, três ou dez anos depois, de repente, o assunto volta, então, é hora de voltar a trabalhar nisso. Quando penso
Scholars from

The Interweaving Performance Culture Research Center. 
que terminei, escrevo o que tenho a dizer naquele momento. Penso ser necessário certo tempo para que você sinta que tem que voltar a determinado assunto, sem se repetir, já que isso não faria sentido.

Você se refere à materialidade de uma maneira bem complexa, ao mesmo tempo em que reconhece a diferença entre expressividade e performativo.

Performativo é aquilo que produz o que é executado, e expressividade, você tem que expressar algo que está em outro lugar. No século XVIII, havia livros sobre emoções, e há a ideia por trás, a emoção está em você e precisa ser externada de alguma maneira através de certos movimentos ou expressões faciais; e lida com a ideia do outro sobre a sua emoção. Enquanto hoje, esses gestos e expressões faciais articulam a emoção e, se não estão lá, não há emoção, não há um espaço interno onde a emoção faria algo; é claro que você sente a maioria das suas emoções, no corpo, estômago, tontura. Não se trata de um sentimento que pode ser apreendido, mas uma emoção que se articula fisicamente. Não se expressa, mas articula-se. É diferente. Isso é performativo. É diferente de algo que existe e tenho que expressar.

Parece que a noção de evento não é resolvida.

É novamente um problema da língua. Porque "evento" em inglês não significa exatamente o mesmo que "ereignis" em alemão. Temos filosofia sobre "ereignis", começando com Heidegger, significa algo que acontece apenas uma vez caso contrário, não seria "ereignis". E "evento" em inglês tem muitas outras camadas de significados. Essa é a dificuldade da tradução. Você não apreende exatamente como é. Usei a palavra em inglês no sentido de algo que acontece apenas uma vez e afeta todos que participam disso. Isso é importante, não é criar uma mitologia em torno de algo, ou fazer um mistério sobre as performances. É claro que você pode repetir, mas não pode repetir a constelação daquele momento. Quer dizer, se você tiver os mesmos espectadores, eles responderão de forma diferente. Se você tiver outros espectadores, também acontecerá apenas uma vez. Para cada um que estiver lá, será uma experiência única, o mesmo acontece com o performer. Acontece apenas uma vez porque o performer está em frente a uma plateia, para e com essa plateia, e isso não se repete. Não significa que estou mistificando, não posso repetir? Pode, mas isso não significa que será igual, é outra coisa e isso não é mistificar. 
Por exemplo, você conhece Alain Badiou? Ele é um filósofo que escreveu o livro Being and Event. Ele disse, "evento é um buraco no seu conhecimento prévio" - quando você vive a experiência de um evento, isso significa que você está encarando algo que produzirá um buraco no seu conhecimento prévio, você encara o desconhecido.

Isso é um problema de semântica, porque as palavras que temos nas línguas são performativas e não expressivas. Não existe "evento", isso não existe. É um conceito, e conceito é uma ferramenta heurística: então, definirei isso dessa maneira, porque tenho determinadas ideias que quero expressar, portanto, preciso desse conceito para substituí-las. Ou você e eu temos intenções diferentes, mas ambos precisamos do termo "evento", mas desde que temos horizontes diversos nos quais queremos inserir isso, definimos a mesma palavra de formas diferentes. Então, eu nunca me incomodei com isso. Penso ser um erro que muitos dos alunos, até os avançados, fazem, "para ele evento é isso, para ela é aquilo". Tudo bem, porque esta cadeira existe e quando nego sua existência ou vou contra isso, sinto que existe de qualquer maneira. Mas evento não existe como uma cadeira. Evento é uma construção na minha cabeça. Portanto, sempre digo que não é que qualquer conceito sirva, mas é uma ferramenta heurística, eu defino de uma maneira particular que coloca em evidência os aspectos que são interessantes e importantes na minha teoria. E se outra pessoa utiliza outra definição, não é algo que incomode. Há diferentes conceitos. Importante é saber quais desses conceitos fazem sentido nessa teoria, e não fariam o mesmo em outra teoria.

Considerando sua visão pessoal, você diria que evento é uma ruptura?

Bem, isso é importante, não é uma ruptura, mas algo que quando acontece, nada será mais o mesmo, não estou me referindo a não podermos percorrer duas vezes o mesmo rio. Claro que não, e não me importo se o rio muda ou não. Mas evento acontece quando realmente significa algo para você, quando lhe afeta emocionalmente e cognitivamente.

Então, de certo modo, o evento é um deslocador.

Sim, pode ser.

Você consegue diferenciar um antes e depois do evento.

Sim. 
The Interweaving Performance Culture Research Center, você poderia falar um pouco sobre isso? Qual o objetivo desse centro?

Bem, a ideia é que nos anos 80 nós apoiávamos os teatros interculturalistas, cheguei a dar palestras sobre o assunto. Já tínhamos isso muito antes, mas na época houve um grande destaque quando artistas começaram a produzir seus trabalhos utilizando elementos de diferentes culturas; por exemplo, Peter Brook em Mahabharata, usando elementos do teatro da Índia, ou Bob Wilson em The Knee Plays, com influência do teatro japonês ou Suzuki quando fez Trojan Women, combinando elementos do Japão com o Ocidente. Tudo isso era considerado teatro intercultural. Mas somente as produções ocidentais eram denominadas assim, algo da África ou China não. E isso fez com que eu desconfiasse desse termo. Não trabalhei mais com isso, estava em outro lugar, e quando voltei, há uns anos, tinha tanta coisa acontecendo. Voltei a esse assunto, porque havia muita coisa, companhias de dança utilizando danças de diferentes culturas, muita troca entre pessoas, textos e workshops. Foi quando me interessei em saber o que acontece quando essas coisas são colocadas juntas e comparadas, diante e com plateias diferentes; o que de diferente pode acontecer. E agora em um mundo globalizado, isso é bastante frequente. Por um lado, ainda temos certas formas teatrais como na Índia, China, Tailândia e também na África consideradas tradicionais, mas elas também mudam. Mas, por outro lado, é hilário ver pessoas no Ocidente que acham que nosso teatro mudou muito desde a Idade Média, mas, por outro lado, insistem que Kabuki, Kathakali e Beijing Opera não mudam. Eles começaram com essa visão sobre o nosso balé, o clássico é o mais próximo que temos desse assunto. Mas todas essas formas mudam em determinada direção. É fascinante hoje ver o que acontece com o teatro, já que não é algo que se encapsula, como um livro, escultura ou pintura. Tem que ser recriado hoje, aqui e agora. O que estamos fazendo então com essas formas diferentes? Quer dizer, todos conhecemos Marcel Mauss e Les Techniques Du Corps, ele descreve que todos os seres humanos são capazes de correr, sentar, andar, cantar, subir, nadar etc., mas cada um faz isso de um jeito diferente, porque a cultura faz com que seja diferente. Então até aqui tudo bem, mas, o que acontece quando a mesma pessoa faz workshops e treina a partir de diferentes técnicas corporais? Elas deixaram uma marca em seu corpo. E o que acontece? Se essa pessoa lida com essas questões sobre a não existência de formas tradicionais puras, e então a questão é, quando algo é feito, o que pensamos? É culturalmente criado e produzido? Ou apenas colocamos várias coisas juntas, daqui e dali, sem fazer sentido, a não ser o fato de saber usar todas essas coisas? 
É muito diferente. E trabalhamos com isso, junto com nossos colegas do mundo todo, pesquisando por um ano e tendo várias discussões juntos.

\section{Em Berlim?}

Lá do outro lado da rua, naquela casa. É muito produtivo.

\section{É possivel se inscrever?}

Sim, mas temos requisitos, você tem que ter Doutorado - para cada pesquisador com Doutorado, tem que haver dois Pós-Doc; mas não com o objetivo de reescrever uma dissertação ou livro, tem que ser um novo projeto. Normalmente temos duas posições para artistas: é importante ter artistas, nós os escolhemos cuidadosamente, já que tem que ser alguém que reflita sobre o próprio trabalho, e tanto eles quando nós possamos aproveitar a experiência e trocar. No momento, há dois artistas fantásticos da Índia. Somos dez, é um intercâmbio, um grupo vigoroso, temos discussões maravilhosas e espero que as pessoas escrevam livros a partir dessa experiência aqui.

\section{É um time permanente?}

A cada ano novas pessoas vêm, é um instituto para estudos avançados, mas com a diferença que, em outros, há muitos assuntos, enquanto aqui temos apenas um; somente pesquisadores podem se inscrever, não só de teatro, de outras áreas também. $\mathrm{O}$ foco não está em uma disciplina, mas nesse assunto único, e quem puder contribuir pode se inscrever.

\section{A pessoa fica por um ano?}

Doze meses, algumas dividem em dois semestres, ou quatro bimestres, tudo é possivel.

A noção de interdisciplinaridade é uma prática crescente hoje em dia, você acredita tratar-se de uma tentativa de estabelecer um dialogo entre o teatro e as ciências cognitivas?

Sim, eu passei por essa experiência por doze anos nesse centro patrocinado pelo German Research Council on Performing Culture, e era totalmente interdisciplinar. Penso que interdisciplinaridade faz sentido somente com bases sólidas. Cada um tem que ser muito bom na sua área - então você pode trocar. Eu diria que há uma grande diferença entre as Ciências Naturais e as Humanidades. Nas Ciências Naturais, você tem artigos sobre dez assuntos. Nas Humanidades, isso não faz sentido, 
pois cada escritor escreve seu livro de maneira diferente da que se não houvesse uma discussão. Então, nós nos encontrávamos a cada 15 dias de quarta feira, e havia outros quatro grupos de trabalho para coisas especiais. Era muito bom. Eu sinto falta e me sinto feliz de ter passado por isso, porque foi maravilhoso o que aprendi. Isso só é possível na interdisciplinaridade. Caso contrário, não pode ser feito a partir da perspectiva de uma única disciplina.

\section{A língua utilizada no instituto é o inglês?}

Nossa língua oficial é a inglesa, porque temos gente do mundo todo. É estranho, pois há colegas japoneses fluentes em alemão que não falam o inglês tão bem; mas nossos colegas mais jovens ajudam e isso não é um problema.

\section{Pode falar resumidamente sobre sua pesquisa atual?}

No momento, estou escrevendo um livro sobre as produções realizadas a partir de As Bacantes de Eurípedes, no mundo globalizado - chama-se Dionysius Resurrected. A questão é por que desde a montagem de Schechner, Dyonisious'69, temos tido um boom de produções baseadas em Eurípedes. É no que estou trabalhando no momento, e é muito divertido. 